\title{
Primary Total Hip Replacement in The Military Hospital in Kathmandu
}

\author{
Pankaj Chand, ' Sushil Rana Magar, 'Bishnu Babu Thapa, 'Bikal Shrestha ${ }^{2}$ \\ 'Department of Orthopaedics, Nepalese Army Institute of Health Sciences, Kathmandu, Nepal, ${ }^{2}$ Department of Community \\ Medicine, Nepalese Army Institute of Health Sciences, Kathmandu, Nepal.
}

\section{ABSTRACT}

Introduction: Total hip replacement is one of the most widely performed and amongst the most successful orthopedic procedures performed worldwide. Even though it is a common orthopedic procedure in developed nations, it is performed only in selected centers in Nepal. This study will review the functional outcome of total hip replacements carried out in Shree Birendra Hospital.

Methods: We reviewed the records of total hip replacements, which were carried out in Shree Birendra Hospital, Kathmandu. Twenty-one hips were cemented and nineteen were uncemented. Cases were followed up in six weeks, twelve weeks, six months and every year from then on. Outcome in terms of Harris hip score of 40 osteoarthritic hips were measured pre-operatively as well as post-operatively.

Results: The mean age of the patients was 50.63 years (range 22-79 years). The commonest reason for the replacement was primary osteoarthritis of the hip. Thirty-nine patients underwent unilateral total hip replacement while in one patient both hips were replaced. The mean Harris hip score for the forty hips that were available at the latest follow-up examination at an average of five years (range two to six and a half years) after the operation was $85.2 \pm 7.65$ points as compared to the preoperative mean Harris hip score of $32.38 \pm 3.4$.

Conclusions: Based on improved Harris hip scores, we believe that THR is a good option in patients with end stage arthritis of the hip.

Keywords: cemented; primary osteoarthritis; total hip replacement.

\section{INTRODUCTION}

Total hip replacement (THR) is a surgical procedure in which the damaged hip is replaced by a prosthetic implant, thereby converting a painful hip into an almost painless one. It is one of the most successful and cost effective interventions in medicine. ${ }^{1}$

It is used to treat hip joint failure caused by severe osteoarthritis usually in elderly, where it becomes so debilitating that the patient is unable to carry out even activities of daily living. These days though, due to advancement in surgical technique and instruments, old age is no bar. It offers reliable relief of pain and considerable improvement in function in patients suffering with severe osteoarthritis or inflammatory arthritis of the hip.$^{2-5}$

This study will provide a clinical appraisal of the efficacy of hip replacements done in Shree Birendra Hospital in last seven years. The aims of the procedure are pain relief and improvement in hip function in terms of Harris Hip Score.

Correspondence: Dr. Pankaj Chand, Department of Orthopaedics, Nepalese Army Institute of Health Sciences, Kathmandu, Nepal; Email: pankreena@hotmail.com, Phone: +9779851092301. 


\section{METHODS}

This is a retrospective study of forty hip replacements in done in Shree Birendra Hospital, Kathmandu between $24^{\text {th }}$ August 2008 and $4^{\text {th }}$ January 2015. Preoperatively consent was taken from all the patients. The treatment records of forty hips (thirty nine patients) with severely degenerated hips that underwent total hip replacement and followed up for at least 23 months were included in the study. Acute polytrauma cases and those of age below eighteen years were excluded.

All patients were operated with combined spinal and epidural anesthesia, the patients were placed in lateral decubitus position and the procedure was performed using modified Hardinge approach (anterior-lateral) in thirty-five hips, while posterior approach was used in five hips. Prophylactic intravenous antibiotic was given to all patients. Proper rehabilitation protocol was followed post-operatively. Quadriceps exercises (along with foot and ankle exercises) were begun as soon as the patient could tolerate pain. Abductor exercises were begun after the third week, for those with anterior-lateral approach. The wound was inspected on the fifth postoperative day and on the $14^{\text {th }}$ day sutures or staples removed. Patients were followed up in six weeks, twelve weeks, six months and one year after being discharged. There after they were advised an annual visit or earlier if they deemed it necessary.

The data were entered into Excel Sheet and analyzed using statistical software SPSS version 20. Functional outcome in terms of Harris Hip score of 40 osteoarthritic hips were measured pre-operatively as well as postoperatively.

\section{RESULTS}

There were 39 patients amongst which twenty-two were female and seventeen were male. The average age of the patients was 50.63 (range-22 to 79 years). The commonest cause for replacement was primary osteoarthritis (thirty) of the hip. This was followed by post-traumatic osteoarthritis (five), Rheumatoid arthritis (three) and avascular necrosis of the head (two) of femur (Table 1).

\begin{tabular}{|ll|}
\hline \multicolumn{2}{|l|}{ Table 1. Demographic pattern of patients. } \\
\hline Parameters & $\mathrm{n}(\%)$ \\
Male & $17(43.5 \%)$ \\
Female & $22(56.5 \%)$ \\
Etiology of osteoarthritis of hip & \\
Primary osteoarthritis & $30(75 \%)$ \\
Post traumatic osteoarthritis & $5(12.5 \%)$ \\
Rheumatoid arthritis & $3(7.5 \%)$ \\
Avascular necrosis & $2(5 \%)$ \\
\hline
\end{tabular}

Thirty-eight patients underwent unilateral THR and one patient underwent bilateral THR. There was one case of superficial infection that resolved with antibiotics and dressing. No evidence of loosening was seen in any patient. One patient had foot drop, which corrected spontaneously after three months. Both cemented $(57.5 \%)$ as well as uncemented $(42.5 \%)$ hips are functioning well at the time of this article's submission.

The mean Harris hip score for the forty hips that were available at the latest follow up examination at a mean of five years (range - two to six and a half years) after the operation was $85.2 \pm 7.65$ points as compared to the pre-operative mean HHS of $32.38 \pm 3.4$ (Tables 2).

Table 2. Showing the comparison in Harris Hip Scores (pre and post operatively).

\begin{tabular}{lll|}
\hline Parameters & HHS (Pre & HHS (Post \\
Op) & Op) \\
Mean & 32.13 & 85.23 \\
Standard Error of & 0.575 & 1.204 \\
Mean & 31.50 & 85.00 \\
Median & 3.639 & 7.617 \\
Standard Deviation & 25 & 50 \\
Minimum & 40 & 95 \\
Maximum & & \\
\hline
\end{tabular}

There was a significant improvement in hip function after the hip replacement as was evident from the postoperative hip scores. On the basis of the Harris hip scores, fourteen hips had excellent results, twenty-two had good results and four had a fair result, at the latest follow-up examination (Figure 3 ).

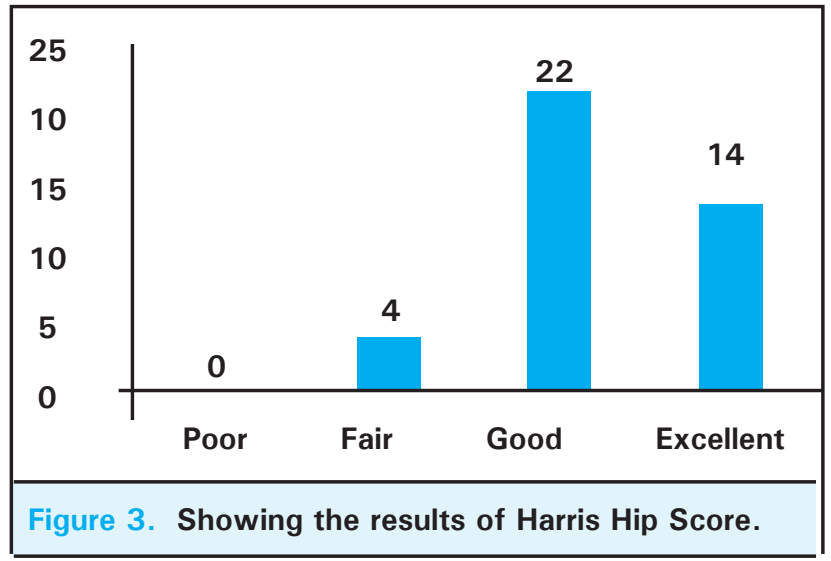

\section{DISCUSSION}

Total hip replacement is one of the most successful surgical interventions of the twentieth century. Hip replacement is usually considered only after other conservative modalities, such as physical therapy and pain medications have failed. 
Pain appears to be a good outcome measure because it correlates with patient opinion, predicts revision and does not fluctuate unduly $\mathrm{Kc}$ et $\mathrm{al}^{6}$ have shown that combined spinal epidural analgesia effectively manages post operative pain, and reduces the risk of deep vein thrombosis and thromboembolism. Similar procedure was carried out in our hospital and none complained of any significant discomfort post operatively.

Long term implant survival is the benchmark for any joint arthroplasty. Our study though is still in its infancy, compared to other studies around the world. Callaghan et al in their research of Charnley's cemented total hip replacement showed almost (78\%) survival in 35 years. ${ }^{7}$ We used cemented implants in 21 (52.5\%) of our cases and all are doing well till now.

Cement less fixation has been performing well over the last three decades. Yamasaki et al demonstrated good results with cement less stem fixation over ten years ${ }^{8}$. Stefl et al showed appreciable results in 20 years with their work on cement less acetabular fixation. ${ }^{9}$ We also used cement less acetabular and femoral fixation in nineteen $(47.5 \%)$ of our cases. They are all doing well. It has been proved that hydroxyapatite coating improves the longevity of the implants. ${ }^{10}$ Both the cement less components (acetabular and femoral) in our series were coated with hydroxyapatite and we have had no complains yet.

Venous thromboembolism is one complication, which we all want to avoid during joint replacement. Various drugs, through oral as well as parenteral routes, along with mechanical devices are available today for it prevention. Aspirin has been a favored drug for preventing venous thromboembolism since long. ${ }^{11}$ Moreover it is also cost effective, ${ }^{12}$ but because some patients cannot tolerate it, we resorted to taking another option. Enoxaparin has proved to be effective when given subcutaneously, ${ }^{13,14}$ even though it did not appear to be more effective (in the Indian population) by some..$^{15}$ In our institute, we use Enoxaparin $(40 \mathrm{mg}$ subcutaneously once daily) for one week only. We have not yet encountered any serious thromboembolic episode.

Intraoperative as well as post operative bleeding is one complication beyond human control. There are various methods by which it can be controlled within appreciable limits. Tranexamic acid is one such drug as shown by Hourlier et al. ${ }^{16}$ In fact another research by Konig et al showed that, topical application of Tranexemic acid reduces post operative bleeding. ${ }^{17}$ In our hospital, we give a single dose of Tranexemic acid (1 gram) as infusion pre operatively. We have not encountered any episode of significant bleeding peri-operatively.
Recently, concern has emerged about pseudo tumors after hip arthroplasties with metal on metal bearings. We have carried out metal on metal hip arthroplasty in three cases. Metal on metal bearings, although, reduce THA wear dramatically, but metal wear particles can lead to delayed hypersensitivity reactions. Their local responses comprise a clinical spectrum ranging from soft tissues as well as osseous changes. ${ }^{18,19}$ However, there are other reports of metal on metal bearings with better results mainly due to less osteolysis, ${ }^{20}$ especially in young and active patients. ${ }^{21}$ But as these were published before the concern regarding pseudo-tumors arose, in our institute, we don't perform metal on metal arthroplasty anymore.

Incidences of femoral fractures while performing a hip arthroplasty have been reported in various literatures. Brun and Maansson reported fractures of the greater trochanter, while performing hip arthroplasty in their research paper. $^{22}$ In our series, there were three fractures of the femur. Two were around the lesser trochanter region and one more distally. The first two were managed with cerclage wiring, while the third was managed by bone grafting and inserting the femoral stem beyond the perforation.

Dislocation has been described as one of the commonest complication after total hip arthroplasty. ${ }^{23}$ It can be managed conservatively in most cases but Goetz et al showed how to salvage a recurrent dislocation best in their paper. ${ }^{24}$ In our series, no dislocation has occurred post operatively till now.

Infection, as we all know is the most dreadful complication after a total joint arthroplasty. Over the years, it has been brought down to less than one percent in most large centers. ${ }^{25}$ In our series, it was one case out of 40 (2.5\%). Post operative care has formed the basis of a successful well functioning hip after surgery. It is necessary for the rehabilitation team to pursue that goal. Ververeli et al have shown that, to reduce post operative complications and move at a rapid pace of recovery one has to adhere to certain guidelines. ${ }^{26}$ In our series, there was one superficial infection, which was managed conservatively.

In our study, the functions of the operated hips showed a marked improvement as was evident from the raised post operative HHS that was comparable to the study carried out by Bourne RB et al. ${ }^{27}$

\section{CONCLUSIONS}

Overall, all patients had a good outcome of the operated hips as was evident from their improved Harris Hip Scores. There were no lasting complications. Based on our limited experience, we believe that THR is safe and 


\section{REFERENCES}

1. Liang $\mathrm{M}$, Cullen $\mathrm{K}$, Larson $\mathrm{M}$, Thompson M, Schwartz J, Fossel A. Cost effectiveness of total joint arthroplasty in osteoarthritis. Arthritis Rheum.1986;29:937-43. [PubMed]

2. Jonsson B, Larsson S. Functional improvements and costs of hip and knee arthroplasty in destructive rheumatoid arthritis. Scand J Rheumatol. 1991;20:351-7. [PubMed]

3. Rissanen P, Aro S, Slatis P, Sintonen H, Paavolainen P. Health and quality of life before and after hip or knee arthroplasty. J Arthroplasty. 1995 Apr;10(2):169-75. [PubMed]

4. Wiklund I, Romanus B. A comparison of quality of life before and after arthroplasty in patients who had arthrosis of the hip joint. J Bone Joint Surg Am. 1991 Jun;73(5):765-9. [PubMed]

5. Laupacis A, Bourne R, Rorrabeck C, Feeny D, Wong C, Tugwell $\mathrm{P}$, et al. The effect of elective total hip replacement on health related quality of life. J Bone Joint Surg Am. 1993 Nov;75(11):1619-26. [PubMed]

6. NB KC, S Rai, P Chand, A Joshi, BR Kunwar. Combined spinal epidural anesthesia for total hip replacement surgery in Birendra Army Hospital. Medical Journal of Shree Birendra Hospital. 2011;10(2):32-6. [․ㅏll Text]

7. Callaghan JJ, Bracha P, Liu SS, Piyaworakhun S, Goetz DD, Johnston RC. Survivorship of a Charnley total hip arthroplasty: a concise follow-up, at a minimum of thirty-five years, of previous reports. J Bone Joint Surg Am. 2009 Nov;91(11):2617-21. [PubMed]

8. Yamasaki T, Yasunaga Y, Mori R, Hamanishi M, Shoji T, Ochi M. The Cementless Spotorno stem in THA: 10 year results. Hip Int. 2014 Mar 12;24(1):98-102. [ubMed]

9. Stefl MD, Callaghan JJ, Liu SS, Pedersen DR, Goetz DD, Johnston RC. Primary cementless acetabular fixation at a minimum of twenty years of follow-up: a concise update of a previous report. J Bone Joint Surg Am. 2012 Feb 01;94(3):234-9. [PubMed]

10. Dumbleton J, Manley MT. Hydroxyapatite-coated prostheses in total hip and knee arthroplasty. J Bone Joint Surg Am. 2004 Nov 01;86(11):2526-40. [PubMed]

11. Parry M, Wylde V, Blom AW. Ninety-day mortality after elective total hip replacement: 1549 patients using aspirin as a thromboprophylactic agent. J Bone Joint Surg [Br]. 2008;90-B:306-7. [PubMed]

12. Schousboe JT, Brown GA. Cost-effectiveness of low-molecular-weight heparin compared with aspirin for prophylaxis against venous thromboembolism after total joint arthroplasty. J Bone Joint Surg Am. 2013 Jul 17;95(14):1256-64. [PubMed]
13. Lieberman JR, Pensak JM. Prevention of venous thromboembolic disease after total hip and knee arthroplasty. J Bone Joint Surg Am. 2013;95:1801-11. [uued]

14. Fitzgerald RH Jr, Spiro TE, Trowbridge AA, Gardiner GA Jr, Whitsett TL, O'Connell MB et al. Prevention of venous thromboembolic disease following primary total knee arthroplasty. J Bone Joint Surg Am. 2001 Jun;83-A(6):900-6. [PubMed]

15. Jain V, Dhal AK, Dhaon BK, Pradhan G. Deep vein thrombosis after total hip arthroplasty in Indian patients with and without Enoxaparin. J Orthop Surg (Hong Kong). 2004 Dec;12(2):173-7. [uuMed]

16. Hourlier H, Fennema P. Single tranexamic acid dose to reduce perioperative morbidity in primary total hip replacement: a randomised clinical trial. Hip Int. 2014;24(1):63-8. [PubMed]

17. Konig G1, Hamlin BR, Waters JH. Topical tranexamic acid reduces blood loss and transfusion rates in total hip and total knee arthroplasty. J Arthroplasty. 2013 Oct;28(9):1473-6. [PubMed]

18. Bisschop R, Boomsma MF, Van Raay JJ, Tiebosch AT, Maas M, Gerritsma CL. High prevalence of pseudotumors in patients with a Birmingham hip resurfacing prosthesis: a prospective cohort study of one hundred and twenty-nine patients. J Bone Joint Surg Am. 2013 Sep 04;95(17):1554-60. [PubMed]

19. Grammatopoulos G, Pandit H, Kwon YM, Gundle R, McLardy-Smith P, Beard DJ, et al. Hip resurfacings revised for inflammatory pseudotumour have a poor outcome. J Bone Joint Surg Br. 2009 Aug;91(8):1019-24. [PubMed]

20. "Asymptomatic" Pseudotumours after metal-on-metal hip resurfacing arthroplasty: prevalence and metal ion study. J Bone Joint Surg Br. 2011;93-B(SUPP I):66-7. [Full Text]

21. Amstutz HC, Le Duff MJ, Campbell PA, Gruen TA, Wisk LE. Clinical and radiographic results of metal-on-metal hip resurfacing with a minimum ten-year follow-up. J Bone Joint Surg Am. 2010 Nov 17;92(16):2663-71. [uㅏMed]

22. Girard J, Bocquet D, Autissier G, Fouilleron N, Fron D, Migaud H. Metal-on-metal hip arthroplasty in patients thirty years of age or younger. J Bone Joint Surg Am. 2010 Oct 20;92(14):2419-26. [pubMed]

23. Brun OCL, Maansson L. Fractures of the greater trochanter following total hip replacement. Hip Int. 2013;23(2):143-6. [Full Text]

24. Soong M, Rubash HE, Macaulay W. Dislocation after total hip arthroplasty. J Am Acad Orthop Surg. 2004;12(5):314-21. [PubMed] 
25. Goetz DD, Bremner BR, Callaghan JJ, Capello WN, Johnston RC. Salvage of a recurrently dislocating total hip prosthesis with use of a constrained acetabular component: a concise follow-up of a previous report. J Bone Joint Surg Am. 2004 Nov 01;86(11):2419-24. [PubMed]

26. Haddad FS, Muirhead-Allwood SK, Manktelow ARJ, Bacarese-Hamilto. Two-stage uncemented revision hip arthroplasty for infection. J Bone Joint Surg [Br]. 2000;82-B:689-94. [Full Text]
27. Ververeli PA, Lebby EB, Tyler C, Fouad C. Evaluation of reducing postoperative hip precautions in total hip replacement: a randomized prospective study. Orthopedics. 2009 Dec;32(12):889. [PubMed]

28. Bourne RB, Rorabeck $\mathrm{CH}$, Skutek $\mathrm{M}$, Mikkelsen $\mathrm{S}$, Winemaker M, Robertson D. Replacement fixed with so-called second-generation cementing techniques. A ten to fifteen-year follow-up. The Harris Design-2 Total Hip J Bone Joint Surg Am. 1998 Dec; 80(12):1775 -80. [PubMed] 